\title{
Host Range and Genetic Characterization of Ditylenchus dipsaci Populations from Eastern Canada
}

\author{
Sandra Poirier, ${ }^{1,2}$ Nathalie Dauphinais, ${ }^{1}$ Hervé Van Der Heyden, ${ }^{3}$ Pierre-Yves Véronneau, ${ }^{1}$ Guy Bélair, ${ }^{1}$ Valérie Gravel, ${ }^{2}$ and \\ Benjamin Mimee ${ }^{1, \dagger}$ \\ ${ }^{1}$ Saint-Jean-sur-Richelieu Research and Development Centre, Agriculture and Agri-Food Canada, Saint-Jean-sur-Richelieu, QC, \\ J3B 3E6, Canada; ${ }^{2}$ Department of Plant Science, McGill University, Ste-Anne-de-Bellevue, QC, H9X 3V9, Canada; and ${ }^{3}$ Phy- \\ todata Inc., Saint-Édouard, QC, J0L 1Y0, Canada
}

\begin{abstract}
The stem and bulb nematode, Ditylenchus dipsaci, is a plant-parasitic nematode affecting over 500 plant species worldwide. Since 2012, garlic producers from Ontario and Quebec have been particularly affected with economic losses caused by this pest. Reproduction of $D$. dipsaci on a particular host depends on its biological race, and races are unknown for these populations from eastern Canada. As a polyphagous pest, D. dipsaci can possibly be a threat and have negative impact on many crops grown in Quebec, such as field and vegetable crops (e.g., onion). In this study, the host range of four populations of $D$. dipsaci from Quebec and Ontario was determined in a greenhouse experiment using 11 crops. Garlic, onion, and

green onion showed high susceptibility to the nematode, whereas reproduction on potato was poor. No reproduction was observed on corn, soybean, barley, alfalfa, mustard, carrot, and lettuce. These crops could therefore be used as rotational crops in a control program. Thirty-two populations of $D$. dipsaci were also genetically characterized using genotyping-by-sequencing. The comparison of allele frequencies at 481 loci showed that most of the populations had a genotype similar to a reference population from northern Ontario. However, a sample from eastern Quebec exhibited a distinct genotype and will require further phenotyping in a greenhouse to preclude the possibility of a different race.
\end{abstract}

The stem and bulb nematode, Ditylenchus dipsaci, is a plantparasitic nematode causing important economic damage worldwide on a wide variety of plants such as garlic, onion, carrot, broad beans, alfalfa, oat, strawberry, and various ornamentals (EPPO 2004). The species is listed as a quarantine pest by the European and Mediterranean Plant Protection Organization (EPPO 2004). In Canada, D. dipsaci is regulated under the authority of the Plant Protection Act by the Canadian Food Inspection Agency (CFIA), and it is considered a quarantine pest when found on potato (CFIA 2013). Differences between countries concerning the quarantine status of $D$. dipsaci limit the access to the exportation market (Tenuta et al. 2014) owing to the risk for important crops. This nematode has a large host range estimated at over 500 plant species separated in more than 30 different biological races (Sturhan and Brzeski 1991). For plant-parasitic nematodes, a race is composed of individuals from a population that share similar morphological characteristics but that exhibit a difference in their ability to reproduce on a set of differential hosts (Dropkin 1988). Because some races of $D$. dipsaci are polyphagous and some host plants can sustain more than one race, racial identification of $D$. dipsaci is a complicated process (Janssen 1994; Viglierchio 1971). Also, because no genetic markers for racial determination are available, the only way to determine the biological race of a $D$. dipsaci population is to run a host range test.

The occurrence of D. dipsaci on onion and garlic was known in many provinces in Canada for a long time (Fushtey and Kelly 1975; Government of New Brunswick 2018; Hajihassani and Tenuta 2017; Johnson and Kayler 1972; Mountain 1957). However, large

${ }^{\dagger}$ Corresponding author: Benjamin Mimee;

E-mail: Benjamin.Mimee@canada.ca

Funding: This research was carried out with financial support from Agriculture and Agri-Food Canada.

*The $\boldsymbol{e}$-Xtra logo stands for "electronic extra" and indicates that one supplementary table is published online.

Accepted for publication 29 August 2018.

() 2019 The American Phytopathological Society outbreaks of D. dipsaci were only observed recently in garlic (Allium sativum) fields from Ontario and Quebec (RAP 2011). Large infestations can result in crop losses of up to $90 \%$ in garlic fields (Abawi and Moktan 2010). Main symptoms on garlic and onion are swelling, distortion, and malformation of leaves and bulbs. In case of severe infestation, the root basal plate can break away from the bulb, the plant turns yellow and dies, and the bulb rots.

Early and effective detection of $D$. dipsaci is necessary for the implementation of good management practices, which are limited in the absence of host range data. Planting nematode-free garlic seeds only in noninfested sites is an essential part of a good management program against D. dipsaci (Abawi and Moktan 2010). Unfortunately, certified nematode-free garlic seeds are not currently available in Canada. Different disinfecting treatments have been proposed for contaminated seeds, including a hot water bath with or without the addition of nematicides. Unfortunately, this approach is tricky because it will negatively affect seed germination and has a variable efficacy rate in killing the nematodes if the critical temperature inside the plant material is not reached (Krusberg 1961). Addition of formaldehyde improved the method but has been abandoned owing to concerns for human health (Roberts and Matthews 1995). Similarly, many soil fumigation products (e.g., methyl bromide) or nematicides that were used previously have been banned owing to environmental (Mellouki et al. 1992) and health hazards (Calvert et al. 1998). Even if there are a few chemical products available, a large proportion of the garlic production in Canada is under organic management in which chemical control is not an option. Thus, crop rotation with nonhost plants appears as the most sustainable (if not the only) management strategy that could be deployed to control $D$. dipsaci. Finding nonhost plants and determining crops at risk are therefore a priority for the management of $D$. dipsaci. Although essential, obtaining those data can be time-consuming, because it requires greenhouse bioassays for each crop and each Ditylenchus population.

The development of genetic markers for the identification of biological race of $D$. dipsaci would provide an efficient tool to improve decision making in the management of this pest, but it requires a better knowledge of the genetic difference between biological races of $D$. dipsaci. A previous study has shown that $D$. dipsaci populations infesting garlic in Ontario were composed of at least two genetic groups after a cluster analysis, suggesting that there were two 
separate introductions of $D$. dipsaci in Ontario (Qiao et al. 2013). Host preference is probably dictated by many different genetic mechanisms such as the production of specific effectors by parasitism genes or receptors for plant recognition and production of molecules to bypass plant defenses (Blok et al. 2008). Thus, the elucidation of biological races in $D$. dipsaci will necessitate whole genome comparisons on a multitude of different populations. Because whole-genome sequencing of numerous samples is still expensive, genotypingby-sequencing (GBS) (Elshire et al. 2011) represents a promising technique for that kind of study. The method has already proven to be a rapid and cost-effective method to provide genetic information and phylogenetic links in different plant-parasitic nematode species (Mimee et al. 2015).

In this study, both phenotypic and genotypic characterization were done to obtain better knowledge concerning the populations of $D$. dipsaci from eastern Canada. This information is essential for the development of appropriate crop rotation programs and to set the foundation for the development of molecular markers for host specificity.

\section{Materials and Methods}

Nematode populations and DNA extraction. Garlic bulbs were obtained from growers and crop specialists between April 2016 and September 2017. A total of 78 samples were collected: 59 from the province of Quebec, 16 from Ontario, and three from Europe. Ditylenchus sp. were extracted from 20 to $100 \mathrm{~g}$ of tissues randomly picked from each sample (four to 10 cloves) using the Baermann pan method (Townshend 1963). The extraction in Baermann's pan lasted 3 days at room temperature, instead of $24 \mathrm{~h}$ as suggested by the International Plant Protection Convention (2016), to ensure extraction of all nematodes. Then, nematode samples were freeze dried for $24 \mathrm{~h}$, and DNA was extracted using the DNeasy Blood and Tissue kit (Qiagen, Mississauga, ON, Canada), following the manufacturer's instructions. Species confirmation was done using a triplex polymerase chain reaction (PCR) method developed by Jeszke et al. (2015) using the OneTaq DNA polymerase kit (Qiagen) and the primers listed in Table 1 (Jeszke et al. 2015). The PCR included the following steps: denaturation for $3 \mathrm{~min}$ at $95^{\circ} \mathrm{C} ; 35$ cycles at $95^{\circ} \mathrm{C}$ for $30 \mathrm{~s}, 62^{\circ} \mathrm{C}$ for $30 \mathrm{~s}$, and $72^{\circ} \mathrm{C}$ for $30 \mathrm{~s}$; and a final extension at $72^{\circ} \mathrm{C}$ for $5 \mathrm{~min}$. PCR products were separated by electrophoresis on a $2 \%$ agarose gel at $125 \mathrm{~V}$ for $50 \mathrm{~min}$.

In vitro rearing. A total of four populations of $D$. dipsaci were reared separately in Petri dishes on sprouts of yellow pea (cultivar Green Arrow), which is a known host for D. dipsaci isolated from garlic in Ontario (Hajihassani et al. 2016). Two field populations of D. dipsaci, one from Quebec (QC16) and one from Ontario (ON16), were obtained from infested garlic, and two D. dipsaci in vitro cultures were obtained from the Canadian National Collection of Insects, Arachnids and Nematodes representing the two genetic populations from Ontario described by Qiao et al. (2013).

Pea seeds were previously surface sterilized with ethanol $95 \%$ for $5 \mathrm{~min}$, followed by an immersion in a $15 \%$ bleach solution for $20 \mathrm{~min}$. Seeds were then rinsed three times ( $5 \mathrm{~min}$ for each rinsing) in sterile water before being deposited on a 9-cm-diameter Petri dish filled with a nutrient agar medium (BD Difco, Mississauga, ON, Canada) (one seed per Petri dish). Petri dishes were incubated for 3 days at room temperature, to detect contamination from bacteria or fungus and to allow seeds to sprout. Then, one sprouted seed was deposited on a Petri dish filled with Gamborg's B-5 medium with minimal organics (3.2 g/liter; Sigma-Aldrich, St. Louis, MO), agar (8 g/liter; Anachemia, Lachine, QC, Canada), and sucrose (20 g/liter; BioShop, Burlington, ON, Canada).
After 2 weeks of growth, 15 handpicked mixed-stage juveniles and adults of $D$. dipsaci of the population from Quebec (QC16) and from Ontario (ON16) were inoculated near the roots of each sprouted pea. These nematodes were previously extracted from garlic using a Baermann pan. Between 250 and 350 mixed-stage juveniles and adults were handpicked randomly and sterilized by transferring them in contact lens solution and rinsing them in sterile water before the inoculation.

For both $D$. dipsaci in vitro cultures from Ontario, nematodes were already reared on a Gamborg's medium Petri dish. A $1-\mathrm{cm}^{3}$ piece of Gamborg's medium with nematodes was cut off sterile and deposited on another pea sprout in a new Gamborg's B-5 medium Petri dish. All Petri dishes were sealed with Parafilm and incubated in the dark at $23^{\circ} \mathrm{C}$ for at least 3 months.

Host range study. For this assay, 11 crops, generally cultivated in the same regions as garlic production, were tested including garlic, onion (Allium cepa 'Trail Blazer'), green onion (Allium fistulosum 'SSRBO01'), soybean (Glycine max 'P90Y90'), alfalfa (Medicago sativa 'Algonquin'), barley (Hordeum vulgare 'Polaris'), corn (Zea mays 'UT128B'), potato (Solanum tuberosum 'Chieftain'), mustard (Brassica nigra 'Caliente 119'), carrot (Daucus carota subsp. sativus 'Enterprise') and lettuce (Lactuca sativa 'Estival'). The assay was conducted twice in a greenhouse, from October 2016 to January 2017 and from May 2017 to August 2017 to ensure repeatability under different growing conditions. The experiment was conducted using a completely randomized factorial design with the 11 crops as the main factor and the four nematode populations (and a noninoculated negative control) as a subfactor with six replicates of each combination of crop and nematode population. The soil mixture was made of pasteurized beach sand (RONA, Boucherville, QC, Canada) and Promix (Premier Tech Horticulture, Quakertown, PA) in a proportion of $1: 3 \mathrm{v} / \mathrm{v}$. Seeds of onion, green onion, carrot, and alfalfa were planted in microcells 2 weeks before growing the other crops and then transplanted into 12-cm-diameter polyethylene pots filled with 1.5 liters of soil. For the other crops, three to five seeds were planted in each pot. After 2 weeks of growth, the weakest plants were removed, leaving four plants for alfalfa and barley and only one for the other crops. Nematode inoculum for four populations of $D$. dipsaci reared in vitro were prepared by wrapping the culture media into two Kimwipes (Kimberly-Clark, Neenah, WI), immersing in tap water in glass Petri dishes, and incubating at room temperature overnight. The resulting nematode suspensions were poured through a $25-\mu \mathrm{m}$ sieve for nematode enumeration. Nematode inoculation was done by pipetting 200 mixed-stage juvenile and adult nematodes (200- $\mu 1$ solution of water and nematodes) on leaf axils of each plant. The inoculation was done after 1 month of growth for garlic, onion, carrot, and alfalfa and 2 weeks for the other crops. Plants were grown under a 16 -h photoperiod at a day/night temperature of $22 / 20^{\circ} \mathrm{C}$. Eight weeks after inoculation, aerial parts of each plant were cut and weighed, and their height was measured. For some crops, such as garlic, onion, green onion, carrot, and potato, their bulbs or tubers were also harvested and weighed. Nematodes were extracted from each plant (aerial parts plus bulbs or tubers when needed) using the Baermann pan technique and counted under a stereomicroscope (Leica Microsystems, Concord, ON, Canada).

The number of recovered nematodes was analyzed using a Kruskal-Wallis analysis of variance performed in R (R Core Team 2017) using the kruskal_test function from the coin package (Hothorn et al. 2008) with 100,000 permutations.

GBS. DNA extracts from 27 of the field samples as well as two reference populations from Ontario and three external $D$. dipsaci

Table 1. Primers used in the polymerase chain reaction to identify Ditylenchus species

\begin{tabular}{|c|c|c|c|c|}
\hline Species & Primer ID & Sequence & Amplicon size (bp) & Reference \\
\hline D. dipsaci, D. gigas, D. destructor & DITuniF & CTGTAGGTGAACCTGC & - & Jeszke et al. (2015) \\
\hline D. dipsaci & DITdipR & GACATCACCAGTGAGCATCG & 148 & Jeszke et al. (2015) \\
\hline D. gigas & DITgigR & GACCACCTGTCGATTC & 270 & Jeszke et al. (2015) \\
\hline D. destructor & DITdesR & GTTTTTCGCCCACAAATTAGC & 339 & Jeszke et al. (2015) \\
\hline
\end{tabular}


populations from France and Turkey (Table 2) were used for a population genetic analysis. DNA concentration from all samples was quantified using Qubit quantitation assay kit (Thermo Fisher Scientific, Nepean, ON, Canada) following the manufacturer's instructions and normalized to $2 \mathrm{ng} / \mu \mathrm{l}$ by dilution with pure water according to the Qubit concentration for sequencing library construction.

Library preparation was done by the Genomics Analysis Core Facility at the Institute for Integrative and Systems Biology (Université Laval, Quebec, QC, Canada) according to the GBS procedure developed by Elshire et al. (2011) and Mimee et al. (2015) using a combination of Pst1/Msp1 restriction enzymes. Samples were barcoded, multiplexed, and sequenced on five Ion Proton flow cells.

Processing of raw sequences and single nucleotide polymorphism (SNP) calling was done using the Universal Network Enabled Analysis Kit (UNEAK) pipeline (Lu et al. 2013) as described in Mimee et al. (2015). This pipeline is designed to call de novo SNPs, without a reference genome with high stringency. To eliminate sequencing errors, a tolerate rate of 0.03 was used. Filtering of SNPs was done by setting the minimum call rate to 1.0 (no missing data). The minimum minor allele frequency (MAF) threshold was set to 0.01 . Before analysis, SNPs were further filtered with a minimum coverage of 20 reads and a maximum coverage of 10,000 reads. Clustering of $D$. dipsaci populations using principal component analysis (PCA) was performed with the prcomp function from the stats package in $\mathrm{R}$ ( $\mathrm{R}$ Core Team 2017). The fixation indexes $\left(\mathrm{F}_{\mathrm{st}}\right)$ were calculated between each population using standard equations (Hartl and Clark 2007).

\section{Results}

Nematodes with morphological characteristics of the Ditylenchus genus were found in 45 samples, 32 from Quebec and 13 from Ontario. The molecular identification of the collected nematodes confirmed the presence of $D$. dipsaci in all the positive samples. An in vitro rearing was successfully initiated for two of these field

Table 2. Samples of Ditylenchus dipsaci used for genetic characterization

\begin{tabular}{lllc}
\hline Country & Province & \multicolumn{1}{c}{ Region } & ID \\
\hline Canada & Quebec & Montérégie & QC01 \\
Canada & Quebec & Montérégie & QC02 \\
Canada & Quebec & Montérégie & QC05 \\
Canada & Quebec & Montérégie & QC06 \\
Canada & Quebec & Montéregie & QC07 \\
Canada & Quebec & Montérégie & QC09 \\
Canada & Quebec & Quebec & QC10 \\
Canada & Quebec & Montérégie & QC12 \\
Canada & Quebec & Centre-du-Quebec & QC14 \\
Canada & Quebec & Centre-du-Quebec & QC15 \\
Canada & Quebec & Montérégie & QC16 \\
Canada & Quebec & Montérégie & QC17 \\
Canada & Quebec & Laurentide & QC21 \\
Canada & Quebec & Chaudière-Appalaches & QC24 \\
Canada & Quebec & - & QC25 \\
Canada & Quebec & Montérégie & QC27 \\
Canada & Quebec & Estrie & QC30 \\
Canada & Quebec & Estrie & QC36 \\
Canada & Quebec & Estrie & QC38 \\
Canada & Ontario & - & ON16 \\
Canada & Ontario & Wellington & ON42 \\
Canada & Ontario & Wellington & ON44 \\
Canada & Ontario & Wellington & ON45 \\
Canada & Ontario & Wellington & ON46 \\
Canada & Ontario & Niagara & ON47 \\
Canada & Ontario & Wellington & ON48 \\
Canada & Ontario & Norfolk & ON50 \\
Canada & Ontario & Lanark & RefN \\
Canada & Ontario & Hamilton & FRP \\
France & - & - & TUA \\
Turkey & - & - & \\
Turkey & - & - & \\
\hline & & &
\end{tabular}

populations (one from Quebec and one from Ontario) as well as two reference populations (southern and northern Ontario). All Ditylenchus populations developed well on pea sprouts. Nematodes were in good shape and moved well.

Host range evaluation. The host range on 11 crops was tested for four $D$. dipsaci populations. There were no significant differences $(P>0.05)$ between the host range for the two repetitions in time, so the datasets were pooled before analysis. All the populations reproduced well on garlic, onion, and green onion (Fig. 1). The field populations of $D$. dipsaci (Ontario and Quebec) showed a greater reproduction on garlic when compared with the reference populations. On the other hand, the field population from Quebec showed a lower reproduction on green onion. Only a few nematodes were recovered from potato for all the populations. No nematode was recovered from any of the other plant tested: corn, soybean, barley, alfalfa, mustard, carrot, and lettuce.

No significant difference in plant height $(P=0.8874)$ or fresh weight $(P=0.7919)$ was observed between inoculated and noninoculated plants.

GBS. The genetic diversity of 27 field populations of $D$. dipsaci collected from Quebec and Ontario was compared with the two reference populations from southern and northern Ontario as well as three international populations (France and Turkey). A total of $109,337,446$ reads were used. UNEAK pipeline identified 5,617 SNPs, and 481 of those were kept after filtering (MAF $=0.01$ and minimum coverage $=20$ ) and removing loci with missing data.

PCA based on the allele frequencies at these 481 loci showed that most of the 32 populations of $D$. dipsaci clustered together (Fig. 2). This includes all the populations from Quebec and Ontario except one outlier sample from the Chaudière-Appalaches region in Quebec. Populations from Turkey and France were clearly separated by the first axis that explained $28.8 \%$ of the total variation.

Genetic differentiation among populations of $D$. dipsaci was estimated by calculating the fixation index $\left(\mathrm{F}_{\mathrm{st}}\right)$ between each pair of populations (Supplementary Table $\mathrm{S} 1$ ). The highest $\mathrm{F}_{\mathrm{st}}$ values (0.39 to 0.66) were obtained when comparing populations from France and Turkey to Canadian populations. The outlier population from Quebec (QC24), also yielded high $\mathrm{F}_{\mathrm{st}}$ values (0.40 to 0.56 ) when compared with other populations from Quebec and Ontario, supporting the result observed in the PCA. Lower $\mathrm{F}_{\mathrm{st}}$ scores were calculated between populations from Ontario and Quebec. With the exception of the outlier QC24, the average $\mathrm{F}_{\text {st }}$ between populations from Quebec was 0.19. The lowest $F_{\mathrm{st}}(0.05)$ was observed between a population from Quebec and one from Ontario (QC17 and ON47).

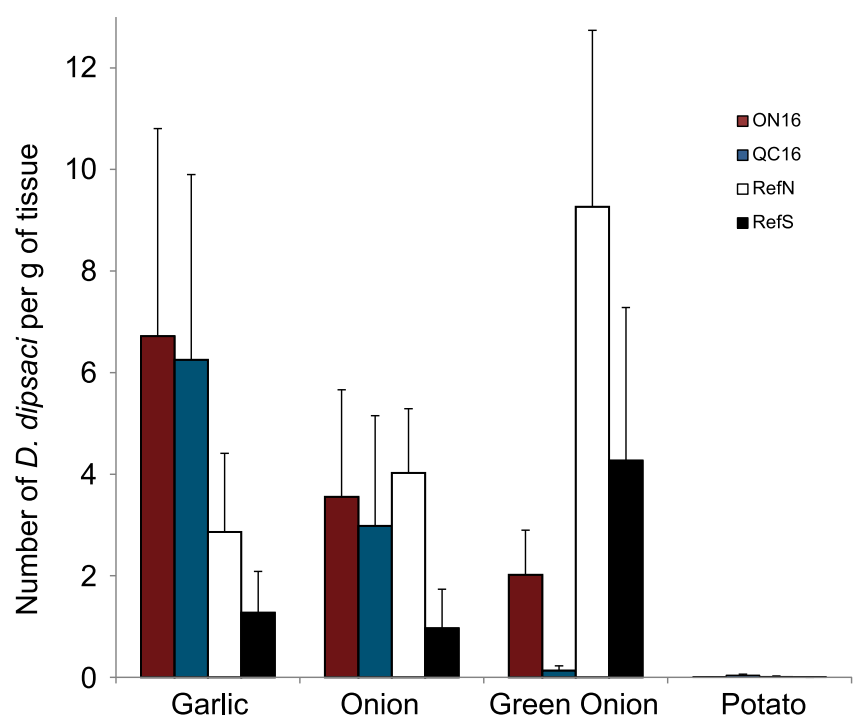

Fig. 1. Host range of four populations of Ditylenchus dipsaci from Quebec and Ontario. Recovered number of $D$. dipsaci per gram of plant tissue 8 weeks following inoculation of four different crop types with 200 mixed-stage juvenile nematodes per plant from four different populations. Error bars represent the standard error of 12 replicates. 
This Ontarian population (ON47) showed close links (low $\mathrm{F}_{\mathrm{st}}$ values) to all the populations from Quebec with an average $F_{\text {st }}$ of 0.11 (when excluding the outlier isolate).

\section{Discussion}

The stem and bulb nematode has been known to be present in North America since the early 1930s (Hodson 1934). However, there appears to be a resurgence in recent years, because major infestations are reported all over New England (Abawi and Moktan 2010), eastern Canada (RAP 2011), and western Canada (Hajihassani and Tenuta 2017), as well as a first mention in Ohio (Testen et al. 2014) and Minnesota (Mollov et al. 2012). Because crop rotation is a critical part of an effective management plan, it is important to have a good knowledge of host plants. It is generally assumed that populations of "garlic and onion" race can develop on Allium (garlic, onion, leek, etc.), pea, snap bean, and some weeds including hairy nightshade (Edwards and Taylor 1963; Sayre and Mountain 1962). However, major variations were reported in the literature about host range. For example, Edwards and Taylor (1963) showed that a population isolated from onion in Illinois reproduced well on soybean and to a lesser extent on tomato. On the contrary, Sayre and Mountain (1962) tested another population, also isolated from onion around the same years in nearby southwestern Ontario, that was unable to reproduce on soybean and tomato. A meta-analysis revealed that a high level of intraracial variation exists in host range profiles of D. dipsaci, which questions the relevance of a classification system based on host specificity (Janssen 1994). Hybrids of D. dipsaci between some races were also successfully produced and exhibited host preference that differed from their parents, confirming that races are not a good predictor of pathogenicity (Webster 1967). Nevertheless, the outcome of this interbreeding confirmed that host range variation within populations is genetically controlled.

Until recently, the information about the host range of the $D$. dipsaci populations currently occurring in eastern Canada was limited. A study identified yellow pea as a good host and canola as a good rotation crop for $D$. dipsaci (Hajihassani et al. 2016) but was limited to crops grown in the Canadian Prairies. Our results confirmed that

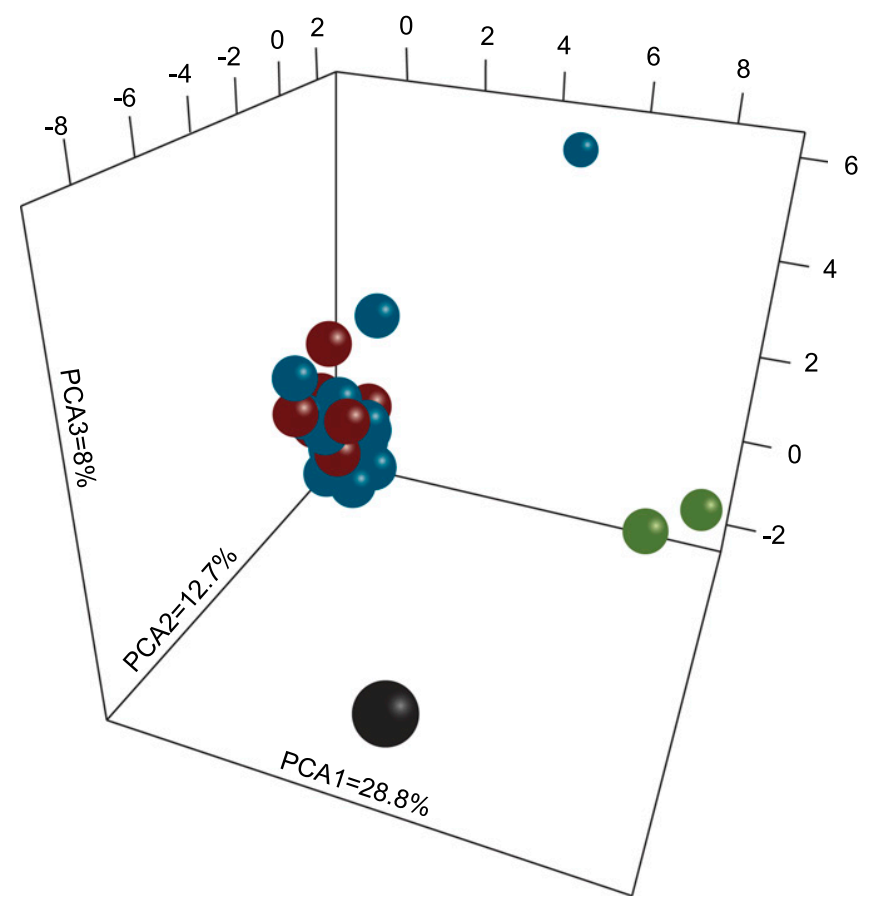

Fig. 2. Principal component analysis of 32 populations of Ditylenchus dipsaci based on genome-wide allele frequencies of 481 loci with no missing data and a minimum coverage of 20 reads/locus/population. Colors represent the different origins of the populations: blue = Quebec (Canada); red = Ontario (Canada); black = France; and green $=$ Turkey.
D. dipsaci isolated from garlic in Ontario and Quebec reproduced well on garlic, green onion, and onion. Production of dry onion in Quebec and Ontario represents a farm gate value of Can\$ 67 million (Statistics Canada 2016). Therefore, limiting the spread of this nematode becomes crucial in order to avoid important losses in garlic and in onion crops. Although limited, reproduction of D. dipsaci was also detected on potato. Following the precautionary principle, potato should not be grown in $D$. dipsaci-infested fields. This recommendation is further supported by the fact that the detection of $D$. dipsaci in potato fields would have important regulation repercussions because $D$. dipsaci is considered a quarantine pest in Canada if found on potato plants (CFIA 2013). Fortunately, it was demonstrated that many interesting options are available as rotational crops for the management of D. dipsaci populations tested in this study, including lettuce, carrot, alfalfa, barley, corn, soybean, and mustard.

Greenhouse host range evaluations are time consuming, and it would be unrealistic to test every population (each field) to validate suitable rotation crops to be used at each location. Here we used a GBS approach to establish the genetic proximity of 32 populations of D. dipsaci. This technique provided thousands of SNPs with good coverage and was found to be a quick and inexpensive alternative to whole-genome sequencing to highlight differences between populations. This analysis revealed that populations of $D$. dipsaci isolated from Quebec and Ontario were genetically very similar. The absence of difference in the host range of the four populations tested supports this finding. Also, pairwise comparisons indicated that most of the populations from Quebec had lower fixation indexes when compared with a single Ontario population (ON47) than with their neighboring populations from Quebec. This strongly suggested that outbreak in Quebec originated from contaminated garlic cloves imported from Ontario. Hajihassani and Tenuta (2017) reported a similar situation in Manitoba: the infestation in the Prairies originated from contaminated garlic seed pieces from Ontario.

Genetic proximity of these populations and their host range similarities obtained in this study suggest that the D. dipsaci populations from eastern Canada could be managed with the same crop rotation program. A notable exception, however, is the population QC24 from the Chaudière-Appalaches region. This population was shown to be genetically distinct and apart from the main cluster in the PCA analysis. Fixation indexes confirmed that this population was different, and it is speculated that it could have been introduced many years before the large outbreak of $D$. dipsaci in Canada. Phenotyping this population for crop preference will be essential for risk assessment and recommendation of crop rotation.

Demand for local garlic has exploded during the last decade in Canada. As a result, the acreage is increasing rapidly in eastern Canada (Statistics Canada 2016). However, the important losses associated with $D$. dipsaci have already convinced several growers to abandon the crop. The deployment of good management practices is therefore crucial to ensure the sustainability of garlic production and to provide farmers a decent income. We confirmed a wide selection of rotational crops to avoid $D$. dipsaci multiplication. Now, the development of a certification program for clean seeds will be essential to limit further contamination.

\section{Acknowledgments}

The authors thank the Réseau d'Avertissements Phytosanitaires, the Ministère de l'Agriculture, des Pêcheries et de l'Alimentation du Quebec (MAPAQ), and Michael Celetti for field sampling, as well as all the farmers involved in the project. The authors also thank Qing Yu from AAFC and Magali Esquibet from INRA for D. dispaci isolates.

\section{Literature Cited}

Abawi, G. S., and Moktan, K. 2010. 2010 bloat nematode problem on garlic: Symptoms, distribution, and management guidelines. Cornell University, Geneva, NY. http://www.hort.cornell.edu/expo/proceedings/2011/Onions \%20\&\%20Garlic/Abawi\%20bloatSum.pdf

Blok, V. C., Jones, J. T., Phillips, M. S., and Trudgill, D. L. 2008. Parasitism genes and host range disparities in biotrophic nematodes: The conundrum of polyphagy versus specialisation. BioEssays 30:249-259.

Calvert, G. M., Mueller, C. A., Fajen, J. M., Chrislip, D. W., Russo, J., Briggle, T., Fleming, L. E., Suruda, A. J., and Steenland, K. 1998. Health effects associated 
with sulfuryl fluoride and methyl bromide exposure among structural fumigation workers. Am. J. Public Health 88:1774-1780.

Canadian Food Inspection Agency (CFIA). 2013. D-98-01: Import requirements for seed potatoes and other potato propagative material. Genome research. CFIA, Ottawa, Canada.

Dropkin, V. H. 1988. The concept of race in phytonematology. Annu. Rev. Phytopathol. 26:145-161.

Edwards, D. I., and Taylor, D. P. 1963. Host range of an Illinois population of the stem nematode (Ditylenchus dipsaci) isolated from onion. Nematologica 9: 305-312.

Elshire, R. J., Glaubitz, J. C., Sun, Q., Poland, J. A., Kawamoto, K., Buckler, E. S., and Mitchell, S. E. 2011. A robust, simple genotyping-by-sequencing (GBS) approach for high diversity species. PLoS One 6:e19379.

European and Mediterranean Plant Protection Organization (EPPO). 2004. Data sheets on quarantine pests: Ditylenchus dipsaci. Europe. EPPO A2 list: No. 174

Fushtey, S. G., and Kelly, C. 1975. A new record of stem and bulb nematode in Ontario. Can. Plant Dis. Surv. 55:27-28.

Government of New Brunswick. 2018. Stem and bulb nematode in New Brunswick garlic fields. https://www2.gnb.ca/content/dam/gnb/Departments/ 10/pdf/Agriculture/Vegetables_Legumes/ StemandbulbnematodeFactsheet2018.pdf

Hajihassani, A., and Tenuta, M. 2017. The occurrence of stem and bulb nematode on garlic in southern Manitoba, Canada in 2015. Can. Plant Dis. Surv. 97:229-232.

Hajihassani, A., Tenuta, M., and Gulden, R. H. 2016. Host preference and seedborne transmission of Ditylenchus weischeri and D. dipsaci on select pulse and non-pulse crops grown in the Canadian Prairies. Plant Dis. 100:1087-1092.

Hartl, D. L., and Clark, A. G. 2007. Principles of Population Genetics. Sinauer Associates, Sunderland, MA.

Hodson, W. 1934. Anguillulina dipsaci (Kühn), as a pest of bulbous irises. J. Helminthol. 12:33-38.

Hothorn, T., Hornik, K., Van De Wiel, M. A., and Zeileis, A. 2008. Implementing a class of permutation pests: The coin package. J. Stat. Softw. 28:1-23.

International Plant Protection Convention. 2016. International Standard for Phytosanitary Measures 27. Diagnostic protocols for regulated pests DP 8: Ditylenchus dipsaci and Ditylenchus destructor.

Janssen, G. J. W. 1994. The relevance of races in Ditylenchus dipsaci (Kühn) Filipjev, the stem nematode. Fundam. Appl. Nematol. 17:469-473.

Jeszke, A., Dobosz, R., and Obrępalska-Stẹplowska, A. 2015. A fast and sensitive method for the simultaneous identification of three important nematode species of the genus Ditylenchus. Pest Manag. Sci. 71:243-249.

Johnson, P., and Kayler, W. 1972. Stem and bulb nematode found in Erieau Marsh, Kent County, Ontario. Can. Plant Dis. Surv. 52:107.

Krusberg, L. 1961. Studies on the culturing and parasitism of plant-parasitic nematodes, in particular Ditylenchus dipsaci and Aphelenchoides ritzeiwabosi on alfalfa tissues. Nematologica 6:181-200.

Lu, F., Lipka, A. E., Glaubitz, J., Elshire, R., Cherney, J. H., Casler, M. D., Buckler, E. S., and Costich, D. E. 2013. Switchgrass genomic diversity, ploidy, and evolution: Novel insights from a network-based SNP discovery protocol. PLoS Genet. 9:e1003215.
Mellouki, A., Talukdar, R. K., Schmoltner, A.-M., Gierczak, T., Mills, M. J., Solomon, S., and Ravishankara, A. 1992. Atmospheric lifetimes and ozone depletion potentials of methyl bromide $\left(\mathrm{CH}_{3} \mathrm{Br}\right)$ and dibromomethane $\left(\mathrm{CH}_{2} \mathrm{Br}_{2}\right)$. Geophys. Res. Lett. 19:2059-2062.

Mimee, B., Duceppe, M.-O., Véronneau, P.-Y., Lafond-Lapalme, J., Jean, M., Belzile, F., and Bélair, G. 2015. A new method for studying population genetics of cyst nematodes based on Pool-Seq and genomewide allele frequency analysis. Mol. Ecol. Resour. 15:1356-1365.

Mollov, D. S., Subbotin, S. A., and Rosen, C. 2012. First report of Ditylenchus dipsaci on garlic in Minnesota. Plant Dis. 96:1707.

Mountain, W. 1957. Outbreak of the bulb and stem nematode in Ontario. Can Plant Dis. Surv. 37:62-63.

Qiao, Y., Zaidi, M., Badiss, A., Hughes, B., Celetti, M., and Yu, Q. 2013. Intraracial genetic variation of Ditylenchus dipsaci isolated from garlic in Ontario as revealed by random amplified polymorphic DNA analysis. Can. J. Plant Pathol. 35:346-353.

R Core Team. 2017. R: A language and environment for statistical computing. R Foundation for Statistical Computing, Vienna, Austria. http://www.R-project. org/.

Réseau d'avertissements phytosanitaires (RAP). 2011. Avertissement Carotte, Céleri, Laitue, Oignon, Poireau [Warning carrot, celery, lettuce, onion, leek] Quebec (Canada), Agriculture, Pêcherie et Alimentation Quebec. https:// www.agrireseau.net/rap/documents/81867/avertissement-no-19-30-septembre2011?r=2011+carotte+c\%C3\%A9leri

Roberts, P. A., and Matthews, W. C. 1995. Disinfection alternatives for control of Ditylenchus dipsaci in garlic seed cloves. J. Nematol. 27:448-456.

Sayre, R. M., and Mountain, W. B. 1962. The bulb and stem nematode (Ditylenchus dipsaci) on onion in southwestern Ontario. Phytopathology 52: 510-516.

Statistics Canada. 2016. Table 001-0013: Area, production and farm gate value of vegetables. CANSIM (database). https://www150.statcan.gc.ca/cansim/a26? lang=eng\&id=10013\&retrLang=eng

Sturhan, D., and Brzeski, M. W. 1991. Stem and bulb nematodes, Ditylenchus spp. Pages 423-464 in: Manual of Agricultural Nematology. W. R. Nickle, ed. Marcel Dekker, New York, NY.

Tenuta, M., Madani, M., Briar, S., Molina, O., Gulden, R., and Subbotin, S. A 2014. Occurrence of Ditylenchus weischeri and not D. dipsaci in field pea harvest samples and Cirsium arvense in the Canadian Prairies. J. Nematol. 46:376-384.

Testen, A. L., Walsh, E. K., Taylor, C. G., Miller, S. A., and Lopez-Nicora, H. D. 2014. First report of bloat nematode (Ditylenchus dipsaci) infecting garlic in Ohio. Plant Dis. 98:859.

Townshend, J. 1963. A modification and evaluation of the apparatus for the Oostenbrink direct cottonwool filter extraction method. Nematologica 9 106-110.

Viglierchio, D. 1971. Race genesis in Ditylenchus dipsaci. Nematologica 17: 386-392.

Webster, J. M. 1967. The significance of biological races of Ditylenchus dipsaci and their hybrids. Ann. Appl. Biol. 59:77-83. 